\title{
Mengapa Punya Sifat Malu Tetapi Melakukan Perilaku Kerja Kontraproduktif?: Peran Moderasi Iklim Etik di Tempat Kerja
}

\author{
Hijriyati Cucuani ${ }^{12}$, Marina Sulastiana ${ }^{2}$, Diana Harding ${ }^{2}$, Hendriati Agustiani ${ }^{2}$ \\ ${ }^{1}$ Fakultas Psikologi Universitas Islam Negeri Sultan Syarif Kasim Riau \\ ${ }^{2}$ Fakultas Psikologi Universitas Padjadjaran Bandung \\ email: hijriyati18001@mail.unpad.ac.id
}

\begin{abstract}
Abstrak
Artikel INFO

Diterima:11 Oktober 2021

Direvisi 1310 oktober 2021

Disetujui:22 November 2021

DOI: http://dx.doi.

org/10.24014/jp.v14i2.14407

Sifat malu (shame-proneness) menjadi salah satu sifat terpuji dalam masyarakat berbudaya kolektif. Individu yang memiliki sifat malu cenderung memperlihatkan tindakan yang sesuai dengan harapan sosial. Namun, perilaku kerja kontraproduktif masih terus terjadi bahkan pada pekerja dengan budaya yang menekankan malu. Iklim etik sebagai faktor situasional yang sering dikaitkan dengan perilaku etik di tempat kerja menjelaskan permasalahan tersebut. Penelitian ini bertujuan untuk mengetahui apakah iklim etik memoderasi pengaruh sifat malu terhadap perilaku kerja kontraproduktif. Berdasarkan uji structural equation modelling terhadap data 404 Pegawai Negeri Sipil di kota Pekanbaru didapatkan Chi-square $=540.04(\mathrm{df}=191), \mathrm{p}=0.000, \mathrm{CFI}=0.98$, NNFI= $0.98, \mathrm{RMSEA}=0.067$, dan $\mathrm{SRMR}=0.012$. Hasil menunjukkan bahwa ada interaksi sifat malu dengan iklim etik dalam mempengaruhi perilaku kontraproduktif pegawai sebesar 0.53 (t-value $=9.56$ ). Dengan demikian, pengaruh sifat malu dalam menurunkan perilaku kerja kontraproduktif diperkuat oleh iklim etik yang positif. Trait activation theory memberikan penjelasan bagaimana faktor situasional turut menentukan bagaimana sifat individu diekspresikan dalam perilaku dibahas di dalam tulisan ini.
\end{abstract}

Kata Kunci: sifat malu, iklim etik, perilaku kerja kontraproduktif

\section{Why Do Employees with Shame-proneness Still Perform Counterproductive Work Behavior?: The Moderating Role of the Ethical Climate in the Workplace}

\begin{abstract}
Shame-proneness is one of the commendable traits in a collective cultured society. Shame-prone people tend to act according to society's expectations. However, counterproductive work behaviors persist even in workers with a culture that emphasizes shame. Ethical climate as a situational factor often associated with ethical behavior in the workplace explains this problem. This study aims to determine whether the ethical climate moderates the effect of shame-proneness on counterproductive work behavior. Based on the structural equation modeling test on the data of 404 Civil Servants in the city of Pekanbaru, it was found that Chi-square $=540.04(\mathrm{df}=191), \mathrm{p}=0.000, \mathrm{CFI}=$ $0.98, \mathrm{NNFI}=0.98, \mathrm{RMSEA}=0.067$, and $\mathrm{SRMR}=0.012$. The results show an interaction between shame-proneness and ethical climate in influencing counterproductive work behavior of 0.53 (t-value $=9.56$ ). Thus, the effect of shame-proneness in reducing counterproductive work behavior is strengthened by a positive ethical climate. Trait activation theory provides an explanation of how situational factors also determine how individual trait is expressed in the behavior, is discussed in this article.
\end{abstract}

Key words: shame-proneness, ethical climate, counterproductive work behavior

\section{Pendahuluan}

Perilaku kerja kontraproduktif menjadi hal yang meresahkan karena merugikan organisasi dan orang-orang didalamnya (Sackett \& Devore, 2005; Spector \& Fox,
2005). Bentuk-bentuk perilakunya dapat berupa dengan sengaja menyakiti orang lain baik secara fisik atau psikologis, melakukan pekerjaan tidak sebagaimana mestinya, merusak atau mengotori properti kerja, mencuri barang atau informasi milik instansi 
dan mengurangi waktu kerja (Spector et al., 2006). Berbagai penyebab telah dicoba digali untuk dapat menjelaskan perilaku ini, diantaranya work stressor (Fida et al., 2015; Fox, Spector, \& Miles, 2001; Roxana, 2013), ethical climate (Kanten \& Ulker, 2013; Bellora-Bienengräbera, Radtke, \& Widener, 2021; Pagliaro, Presti, Barattucci, Giannella, \& Barreto, 2018), personality (Penney \& Spector, 2002; Spector \& Domagalski, 2006) dan emosi negatif (Bauer \& Spector, 2015; Fida et al., 2015; Spector \& Domagalski, 2006), dimana malu ada diantaranya.

Malu yang dalam penelitian ini diteliti sebagai shame, oleh banyak peneliti sebelumnya dijelaskan sebagai emosi yang menyakitkan yang muncul karena pelanggaran dan berdampak buruk (Lewis, 1992; Tangney \& Dearing, 2002). Tangney dan Dearing (2002) menjelaskan bahwa orang dengan sifat yang rentan dalam merasakan malu pada situasi-situasi tertentu disebut dengan shame-proneness (sifat malu). Malu sebagai emosi yang menyakitkan akan membuat orang dengan shame-proneness lebih berpotensi mengalami gejala-gejala psikologis (Tangney \& Tracy, 2012) dan melakukan perilaku kontraproduktif (Spector \& Fox, 2002). Namun, saat ini banyak tulisan menyanggah konsep tersebut dengan menjelaskan sisi positif dari malu sebagai emosi moral. Cohen et al. (2014) justru membuktikan bahwa shame-proneness berhubungan negatif dengan perilaku kerja kontraproduktif. Abraham dan Berline, (2015) berpendapat bahwa negative self-evaluation pada orang dengan shame-proneness justru akan mengantisipasi terjadinya korupsi. Shame-proneness dapat mengarahkan perilaku individu pada ethical behavior (Murphy \& Kiffin-Petersen, 2017).

Perbedaan budaya juga menjadi suatu penyebab berbedanya hasil penelitian mengenai malu (Su, 2010). Malu ada pada setiap masyarakat, tetapi hubungannya dengan yang lain dan perannya dalam masyarakat dapat berbeda pada masyarakat yang berbeda (Bedford, 2004). Pada masyarakat kolektif, keharmonisan dalam hubungan interpersonal adalah hal yang lebih penting (Tinsley \& Weldon, 2003). Oleh sebab itu menjadi lebih rentan merasakan malu setelah melakukan pelanggaran dirasa sudah sewajarnya. Malu bagi masyakat melayu sebagai masyarakat berbudaya kolektif adalah sifat yang dijunjung tinggi karena menyangkut kehormatan dan marwah diri dan keluarga (Effendy, 2015).

Orang dengan sifat malu menunjukkan anticipatory shame yang lebih tinggi (Tangney, Stuewig, \& Mashek, 2007). Anticipatory shame merupakan malu yang membuat seseorang menahan diri agar tidak melakukan sesuatu yang berpotensi menimbulkan kondisi malu (Cucuani, Sulastiana, Harding, \& Agustiani, 2021). Pegawai yang memiliki sifat malu akan lebih berhati-hati dalam bertindak, peka terhadap harapan sosial, mengikuti aturan, sehingga cenderung menghindari tindakantindakan yang tercela dan tidak sesuai aturan. Sifat malu di tempat kerja diharapkan menjadi kontrol bagi pegawai untuk tidak terlibat dalam perilaku kerja kontraproduktif. Namun pada kenyataannya, perilaku kontraproduktif masih saja terjadi (Tim penyusunan Laporan Tahunan KPK 2017, 2018) bahkan di Kota Pekanbaru yang sebagian besarnya bersuku melayu (Suparlan, 1995). Bagi orang melayu, emosi malu paling penting dalam menumbuhkan konformitas (Aknouche \& Noor, 2014), dan berperan sebagai tolak ukur social, menunjukkan indikator dari kepantasan (Goddard, 1996).

Trait Activation Theory menjelaskan bahwa suatu trait (sifat) hanya merupakan kecenderungan untuk menimbulkan perila$\mathrm{ku}$, untuk itu ia membutuhkan situasi yang relevan (Tett \& Guterman, 2000). Pegawai yang memiliki sifat malu dapat saja melakukan perilaku kerja kontraproduktif ketika lingkungannya melemahkan untuk ia merealisasikan sifatnya tersebut. Jika situasi 
sebagai isyarat dipersepsikan tidak relevan dengan sifat malu maka akan menghambat sifat malu distimulus untuk diekspresikan kedalam perilaku yang mencerminkan tindakan dari malu. Salah satu isyarat dalam tingkat organisasi adalah iklim organisasi (Tett, Simonet, \& Brown, 2013). Iklim organisasi yang sering kali dikaitkan dengan perilaku negative, tidak bermoral dan tidak etis adalah iklim etik, yaitu persepsi bersama tentang isi dan kekuatan nilai, norma, sikap, perasaan, dan perilaku yang lazim dari anggota suatu sistem social (unit kerja, departemen, organisasi) (Arnaud, 2006). Dalam hal ini, iklim etik sebagai faktor situasional berperan dalam memoderasi pengaruh sifat malu terhadap perilaku kerja kontraproduktif.

Trait activation theory sebelumnya telah diteliti dalam menjelaskan bagaimana personality traits seperti proactive personality (Philip, 2021), employee core selfevaluations (Bisht \& Mahajan, 2021), big-five personality (Judge, 2015) dimoderasi oleh faktor situasional (job demands-resources, stressors at the group level, innovation/ creativity requirements) berpengaruh dalam

munculkan atau menahan perilaku tertentu. Penelitian sebelumnya yang sangat dekat dengan penelitian ini adalah mengenai pengaruh negative affect terhadap workplace deviance yang dimoderasi ethical climate oleh Chen, Chen, dan Liu (2013). Namun, dalam penelitian tersebut, Chen dkk. meneliti tingkat emosi yang menyedihkan (seperti kemarahan, permusuhan, ketakutan, dan kecemasan) sebagai negative affect dan tidak meneliti sifat malu. Oleh karena itu, penelitian ini diharapkan dapat melengkapi referensi mengenai trait activation theory yang menjelaskan sifat malu pada masyarakat kolektif Budaya Melayu sebagai sebuah trait yang dalam interaksinya dengan factor situasional berdampak terhadap perilaku kerja. Penelitian ini bertujuan untuk mengetahui apakah ada peran iklim etik dalam memoderasi pengaruh sifat malu terhadap perilaku kerja kontraproduktif pada pegawai di Kota Pekanbaru. Dihipotesiskan bahwa iklim etik yang dipersepsikan positif akan memperkuat dampak sifat malu dalam menghambat keterlibatan perilaku kontraproduktif. Kerangka pemikiran penelitian ini dapat dilihat pada gambar 1 berikut:

Gambar 1. Kerangka Pemikiran

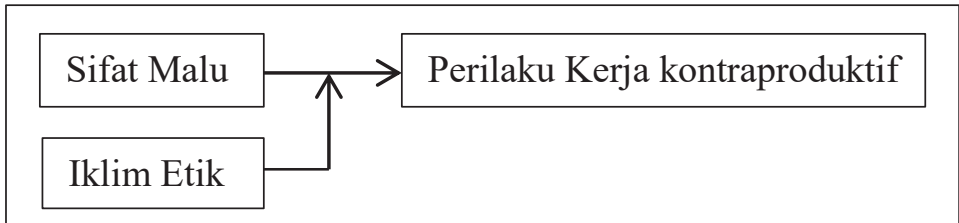

Gambar 1. Kerangka Pemikiran Penelitian

\section{Metode}

\section{Partisipan}

Partisipan dalam penelitian ini adalah Pegawai Negeri Sipil di lingkungan pemerintahan Provinsi Riau di Kota Pekanbaru yang sudah bekerja selama minimal satu tahun di unit kerjanya saat ini. Partisipan dipilih berdasarkan teknik cluster random sampling. Dari 45 instansi yang ada, ditentukan secara acak 19 instansi sebagai lokasi penelitian. Terdapat 404 partisipan yang bersedia mengisi skala secara lengkap. Subjek berusia rata-rata 40 tahun (rentang 20-60 tahun), sudah bekerja sekitar 13 tahun (rentang 1-37 tahun). Subjek berjenis kelamin perempuan sedikit lebih banyak (59.5\%) dibandingkan laki-laki. Sebagian besar subjek berada pada Golongan III (77.4\%), berpendidikan S1 (63.4\%) dan bersuku melayu $(59.9 \%)$. 


\section{Pengukuran}

Perilaku kerja kontraproduktif diukur dengan menggunakan Counterproductive Work Behavior-Checklist (CWB-C) dari Spector et al. (2006) yang telah diadaptasi untuk orang Indonesia (Cucuani et al., 2020). Perilaku kontraproduktif diukur melalui dua dimensi, yaitu perilaku kontraproduktif yang ditujukan kepada organisasi secara langsung (conterproductive work behavior toward organization/CWB-O) dan yang ditujukan pada orang lain di tempat kerja (conterproductive work behavior toward people/CWB-P). Berdasarkan uji validasi menggunakan confirmatory factor analysis (CFA) skala asli yang berjumlah 43 berkurang menjadi 24 guna mendapatkan item dengan factor loading dan kecocokan model yang baik, yaitu nilai chi-square ( $p$-value $)=1588.42$ (0.000), RMSEA $=0.073$. NNFI $=0.92, \mathrm{CFI}=$ 0.92, dan SRMR $=0.072$. Skala CWB-C 24 item terdiri dari 12 item untuk CWB-O (contoh item: Memperpanjang waktu istirahat dari yang ditentukan) dan 12 item untuk CWB-P (contoh item: Membuat lelucon yang mempermalukan seseorang di tempat kerja). Partisipan diminta untuk memberikan respon seberapa sering melakukan tindakan sebagaimana yang dimaksud dalam setiap item selama tiga bulan terakhir. Skor 1 diberikan untuk respon tidak pernah sampai dengan 5 untuk respon selalu. Nilai alpha Cronbach adalah $\alpha=0.866$ untuk CWB secara keseluruhan, 0.835 untuk CWB-O dan 0.747 untuk CWB-P, serta nilai construct reliability $(C R)=0.701$ untuk CWB-O dan 0.709 untuk CWB-P.

Sifat malu diukur menggunakan alat ukur yang disusun oleh peneliti berdasarkan konstruk malu yang didapatkan dari penggalian data kualitatif dilapangan mengenai sifat malu (shame-proneness) pada orang melayu. Uji validasi dengan CFA didapatkan nilai ukuran kecocokan model chisquare $(p$-value $)=373,94(0.000)$, RMSEA $=$ 0.06, NNFI $=0.98, \mathrm{CFI}=0.98$, dan SRMR $=0.067$. Delapan belas item skala shame- proneness terdiri dari delapan item untuk mengukur negative evaluation (contoh item: Saya merasa kurang profesional karena terlambat menghadiri rapat disaat semua anggota sedang fokus mendiskusikan hal penting), empat item mengukur withdrawal (contoh item: Saya merasa ingin menghilang dari hadapan teman-teman saat atasan membentak saya dihadapan mereka) dan enam item mengukur motivation to change the self (contoh item: Performa yang buruk di awal presentasi membuat saya berusaha melanjutkan presentasi dengan lebih maksimal). Subjek diminta untuk me-rating dari 1 hingga 5 seberapa subjek berfikir bahwa masing-masing item sesuai dengan kemungkinan responnya dalam menghadapi situasi-situasi yang tertera dalam skenario terkait peristiwa malu di tempat kerja. Reliabilitas alat ukur tergolong baik, terlihat dari nilai alpha cronbach dan CR sebesar a $=0.894(\mathrm{CR}=0.897), \alpha=0.731(\mathrm{CR}=0.89)$ dan $\alpha=0.892(C R=0,73)$ berturut-turut untuk negative evaluation, withdrawal, motivation to change the self.

Iklim etik diukur menggunakan Ethical Climate Index (ECI) dari Arnaud (2006) yang telah diadaptasi oleh peneliti untuk orang Indonesia. Berdsarkan uji CFA, skala ECI yang aslinya berjumlah 36 item berkurang menjadi delapan belas item dengan tetap mempertimbangkan keterwakilan setiap subdimensi dengan nilai ukuran kecocokan model chi-square ( $p$-value $)=868.38(0.000)$, RMSEA $=0.049, \mathrm{NNFI}=0.98, \mathrm{CFI}=0.98$, dan SRMR $=0.079$. Delapan belas item mengukur ethical climate, dengan tiga item untuk setiap subscale-nya, yang terdiri dari: Norms of Empathic Concern (NEC, contoh: secara umum, orang-orang di unit kerja saya merasa kasihan ketika melihat seseorang diperlakukan tidak adil), Norm of Moral Awareness (NMA, contoh: Orang-orang di unit kerja saya langsung mengenali adanya dilema moral), Focus on Self (FS, contoh: Orang-orang di unit kerja saya memikirkan 
kesejahteraan mereka sendiri dahulu ketika menghadapi keputusan yang sulit), Focus on Others (FO, contoh: Apa yang terbaik bagi setiap orang di unit kerja adalah pertimbangan utama), Collective Moral Motivation (CMM, contoh: Di unit kerja saya, kesuksesan diri lebih penting daripada menolong orang lain) dan Collective Moral Character (CMC, contoh: Orang-orang di unit kerja saya merasa lebih baik bertagung jawab atas kesalahan yang dilakukan daripada lari atau menyalahkan orang lain). Subjek diminta untuk menyatakan kesesuaian pernyataan tiap item dengan persepsinya mengenai iklim etik di unit kerjanya. Skor berkisar antara $1=$ sangat tidak menggambarkan orangorang di unit kerja saya, sampai dengan $5=$ sangat menggambarkan orang-orang di unit kerja saya. Ethical Climate Index secara keseluruhan memiliki Alpha Cronbach $=0.92$, dan Alpha Cronbach (serta CR) 0.823 (0.81), 0.897 (0.81), 0.814 (0.87), 0.838 (0.73), 0.926 (0.87) dan 0.791 (0.78) secara berurutan untuk NEC, NMA, FS, FO, CMM dan CMC.

\section{Kontrol Variabel}

Berdasarkan penelitian sebelumnya, Rentsch and Steel menjelaskan bahwa jenis kelamin usia dan masa kerja turut mempengaruhi perilaku absensi yang juga termasuk kedalam perilaku kerja kontraproduktif (dalam Sackett \& Devore, 2005). Oleh karena itu dalam penelitian ini, jenis kelamin usia dan masa kerja diuji hubungannya dengan variabel-variabel yang diteliti sebelum uji model dilakukan.

Analisis

Penelitian ini menggunakan stuctural equation modeling (SEM) untuk menguji model moderasi iklim etik dalam pengaruh sifat malu terhadap perilaku kerja kontraproduktif. Kriteria kecocokan model yang digunakan mengacu pada Hair et al.(2019), yaitu: chisquare $(x 2)$ dengan $p$ yang tidak signifikan ( $p>$ $0.05)$, root mean square error of approximation (RMSEA) kurang dari 0.08, comparative fit index (CFI) dan tucker lewis index (TLI)/ non-normed fit index (NNFI) diatas 0.95, dan standardized root mean square residual (SRMR) kurang dari 0.08. Dalam melakukan analisis SEM, sebelum dilakukan uji model struktural, dilakukan uji model pengukuran terhadap ketiga variabel terlebih dahulu (Wang \& Wang, 2012). Analisis SEM dalam penelitian ini dilakukan dengan bantuan Program Lisrel versi 8.8. selain itu, dilakukan juga uji korelasi terhadap variabel-varibel yang diteliti serta data demografi dengan menggunakan korelasi product moment, serta uji beda variabel berdasarkan jenis kelamin dengan t-test menggunakan bantuan program IBM SPSS versi 23.

\section{Hasil}

Berdasarkan analisis deskriptif dan analisis korelasi dari data pada setiap variabel ditambah dengan usia dan masa kerja subjek maka didapatkan gambaran sebagai berikut:

Tabel 1. Deskripsi Data Demografi dan Korelasi Variabel Penelitian

\begin{tabular}{llccccccc}
\hline & \multirow{4}{*}{ Variabel } & \multicolumn{4}{c}{ Data Empirik } & \multicolumn{3}{c}{ Korelasi } \\
\cline { 2 - 8 } & & Min & Max & Mean & SD & $\begin{array}{c}\text { Sifat } \\
\text { malu }\end{array}$ & PKP & Iklim etik \\
\hline 1 & Sifat Malu & 19 & 90 & 62.78 & 15.301 & 1 & & \\
2 & PKP & 24 & 120 & 36.21 & 12.928 & $-0.263^{* *}$ & 1 & \\
3 & Iklim Etik & 30 & 91 & 63.25 & 12.172 & $0.423^{* *}$ & $-.309^{* *}$ & 1 \\
4 & Usia & 20 & 60 & 40.47 & 9.441 & -.018 & -.002 & .002 \\
5 & Masa Kerja & 1 & 37 & 13.95 & 8.265 & .008 & .039 & .039 \\
\hline
\end{tabular}

Keterangan: * signifikan pada level $<0.05,{ }^{* *}$ signifikan pada level $<0.01 . \mathrm{PKP}=$ Perilaku Kontraproduktif 
Berdasarkan table 1 di atas diketahui bahwa tidak satupun dari variabel yang diteliti berkorelasi dengan usia dan masa kerja. Selain itu, berdasarkan uji-t variabel sifat malu, perilaku kerja kontraproduktif dan iklim etik berdasarkan jenis kelamin didapatkan nilai t-test (sig) secara berturut-turut -8.39 (0.402), 1.27 (0.204), 0.521 (0.603). Berdasarkan uji beda diketahui bahwa ketiga variabel tidak berbeda secara signifikan berdasarkan jenis kelamin. Oleh sebab itu, baik usia, masa kerja dan jenis kelamin telah terkontrol dalam pengujian selanjutnya.

Berdasarkan analisis confirmatory factor analysis (CFA) dalam analisis model pengukuran pada data setiap variabel maka diketahui bahwa semua item menunjukkan t-value $>1.96$ dan factor loading (standardized) $>0.5$ (Fornell \& Larcker, 1981) terhadap indicator nya masing-masing. Meskipun pada awalnya perilaku kerja kontraproduktif dan iklim etik tidak memenuhi kriteria kecocokan model, namun setelah dilakukan modifikasi dengan membebaskan beberapa eror saling berkorelasi maka didapatkan hasil pengujian yang fit. Dengan demikian model pengukuran dari tiga variabel yang diteliti memenuhi kriteria kecocokan model, sebagaimana ditunjukkan pada tabel 2 berikut:

Tabel 2. Kecocokan Model untuk Sifat Malu, Perilaku Kerja KontraProduktif dan Iklim Etik

\begin{tabular}{lccc}
\hline $\begin{array}{c}\text { Ukuran } \\
\text { Kecocokan Model }\end{array}$ & Sifat Malu & $\begin{array}{c}\text { Perilaku Kerja } \\
\text { Kontraproduktif }\end{array}$ & Iklim Etik \\
\hline Chi-Square & $375.68(\mathrm{df}=128)$ & $1072.35(\mathrm{df}=237)$ & $205.74(\mathrm{df}=118)$ \\
p-value & 0.000 & 0.000 & 0.000 \\
RMSEA & 0.069 & 0.074 & 0.043 \\
NNFI & 0.98 & 0.96 & 0.99 \\
CFI & 0.98 & 0.96 & 0.99 \\
SRMR & 0.053 & 0.064 & 0.041 \\
\hline
\end{tabular}

Berdasarkan table 2 di atas, diketahui dilakukan uji model struktural untuk melihat bahwa baik sifat malu, perilaku kerja apakah model yang diajukan dalam penelitian kontraproduktif dan iklim etik memiliki model ini fit dengan data yang didapatkan secara pengukuran yang tergolong fit. Selanjutnya, aktual.

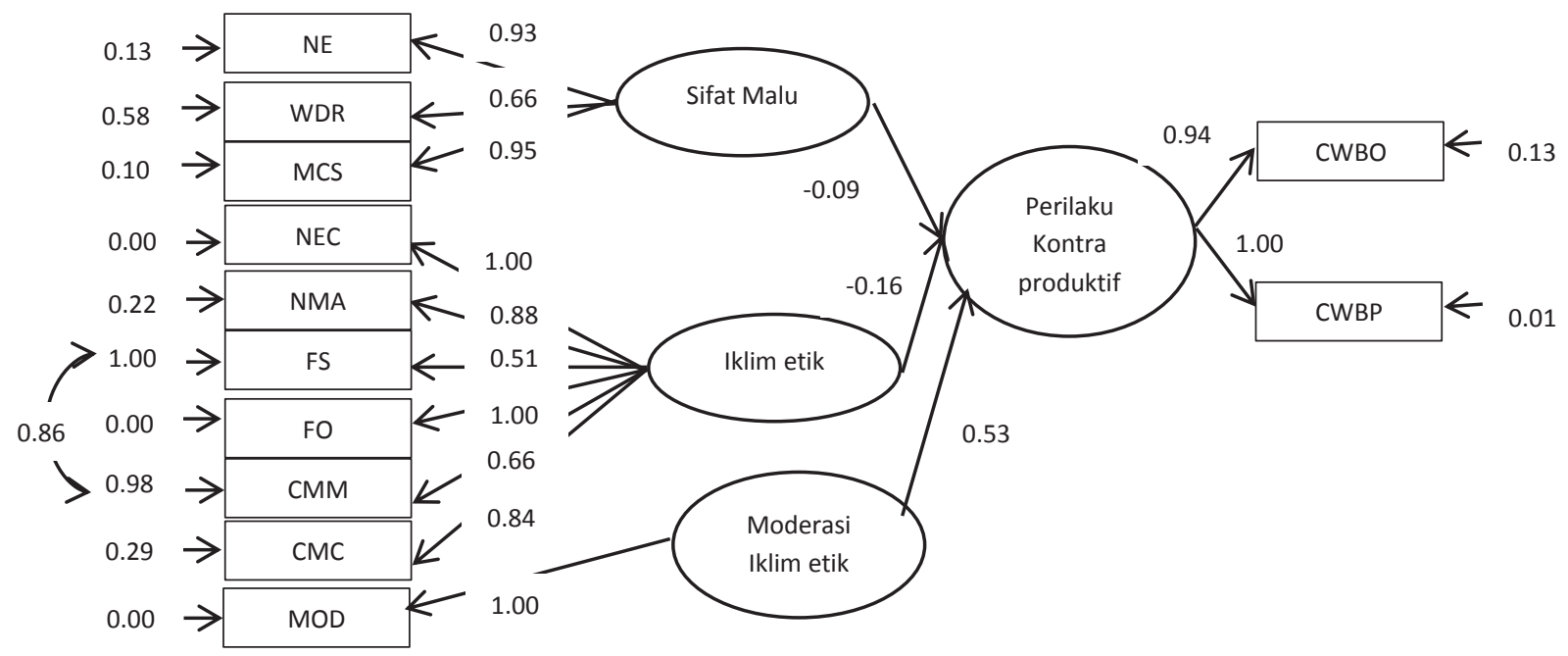

Gambar 2: Model Struktural Moderasi Iklim Etik dalam Pengaruh Sifat Malu terhadap Perilaku Kontraproduktif 
Berdasarkan gambar model struktural muatan factor beserta signifikansi-nya di atas, dapat disimpulkan mengenai nilai sebagaimana dijelaskan tabel berikut:

Tabel 3. Nilai $t$-values dan Standardized Loading Factor Peran Moderasi Iklim Etik dalam pengaruh Sifat Malu terhadap Perilaku Kerja Kontraproduktif

\begin{tabular}{lccc}
\hline \multicolumn{1}{c}{ Uji Peran } & $\begin{array}{c}\text { Nilai } \\
\text { t-Value }\end{array}$ & $\begin{array}{c}\text { Standardized } \\
\text { Loading } \\
\text { Factor }\end{array}$ & Keterangan \\
\hline $\begin{array}{l}\text { Sifat Malu } \rightarrow \text { Perilaku Kerja } \\
\text { Kontraproduktif }\end{array}$ & -1.17 & -0.09 & Tidak signifikan \\
$\begin{array}{l}\text { Iklim Etik } \rightarrow \text { Perilaku Kerja } \\
\text { Kontraproduktif }\end{array}$ & -3.04 & -0.16 & $\begin{array}{c}\text { Peran negatif dan } \\
\text { signifikan }\end{array}$ \\
$\begin{array}{l}\text { Mod Iklim Etik } x \text { Sifat Malu } \rightarrow \\
\text { Perilaku Kerja Kontraproduktif }\end{array}$ & -9.56 & 0.53 & $\begin{array}{c}\text { Peran positif dan } \\
\text { signifikan }\end{array}$ \\
\hline
\end{tabular}

Hasil uji model struktural menunjukkan nilai chi-square yang besar, yaitu $540.04(\mathrm{df}=$ 191) dengan $p=0.000(p<0.05)$. Jika mengacu pada standar ini maka model dinyatakan tidak fit. Namun, index chi-square sensitive terhadap besarnya sampel (Hu \& Bentler, 1999), sehingga Chi-square yang besar tidak selalu berarti menolak hipotesis tidak adanya perbedaan antara matrik input yang diprediksi dengan yang sebenarnya. RMSEAadalah satu ukuran yang paling banyak digunakan dengan upaya mengoreksi kecenderungan statistik Chi-square untuk menolak model dengan sampel besar (Hair et al., 2019). Berdasarkan hasil analisis, didapatkan RMSEA $=0.067$ $(<0.08)$ yang tergolong pada kriteria medium fit. Selain itu, indeks kecocokan model lainnya menunjukkan nilai yang memuaskan dengan $\mathrm{CFI}=0.98, \mathrm{NNFI}=0.98$ dan $\mathrm{SRMR}=0.012$. Berdasarkan uji model struktural terhadap model yang diajukan, maka model tergolong fit.

\section{Pembahasan}

Berdasarkan hasil analisis data diketahui bahwa tidak terdapat pengaruh sifat malu terhadap perilaku kerja kontraproduktif, melainkan dimoderasi secara penuh oleh iklim etik. Tinggi rendahnya pengaruh sifat malu dalam menurunkan perilaku kerja kontraproduktif tergantung dari seberapa positif atau negatifnya iklim etik. Dengan demikian, iklim etik berperan dalam memoderasi pengaruh sifat malu terhadap perilaku kerja kontraproduktif. Dari hasil analisis juga diketahui bahwa iklim etik memiliki pengaruh terhadap perilaku kerja kontraproduktif dalam arah berlawanan.

Iklim etik yang positif menurut Arnaud (2006) adalah ketika pegawai mempersepsi sebagian besar orang-orang di dalam unit kerjanya memahami apa yang baik dan yang buruk secara etik, peka dan peduli terhadap permasalahan etik (norms of moral awareness), menunjukkan empati dengan mempertimbangkan apakah ada orang yang merasa dirugikan atau merasa tidak nyaman sebagai konsekuensi dari keputusan yang diambil (norms of emphatetic concern), tidak mengutamakan kepentingannya sendiri dari pada kepentingan banyak orang (focus on self), lebih mengutamakan dan peduli pada kepentingan dan harapan banyak orang (focus on others). Selain itu, iklim etik yang positif juga tampak dari persepsi pegawai bahwa nilai-nilai moral seperti keadilan, kejujuran dan integritas lebih mendominasi daripada nilai kekuasaan dan pencapaian (collective moral motivation), serta apabila sebagian besar orang-orang di unit kerjanya memperlihatkan keteguhan dan keberanian dalam menjalankan dan mempertahankan 
tindakan etis meskipun ada tekanan (collective moral character). Iklim etik yang positif dapat membuat keterlibatan pegawai terhadap perilaku kontraproduktif menjadi rendah. Ketika pegawai mempersepsi iklim kerjanya positif maka ia akan cenderung tidak melakukan tindakan yang merugikan seperti tidak mengurangi jam kerjanya secara disengaja, tidak berbuat curang, bekerja sesuai instruksi, menggunakan properti kantor dengan baik, serta menjaga kenyamanan orang lain dalam bekerja.

Persepsi pegawai terhadap situasi kerjanya seperti iklim etik merupakan suatu hal yang dapat menstimulasi atau menghambat pengekspresian sifat pekerja untuk menjadi perilaku yang sesuai dengan sifatnya (Tett \& Guterman, 2000). Situasi yang positif akan mendorong pegawai memunculkan sifat positifnya kedalam perilaku positif, demikian pula sebaliknya. Sementara, situasi yang negative akan menghambat sifat positif untuk muncul dalam tindakan yang positif.

Sifat malu bagi orang melayu dipandang sebagai sifat yang positif dan mulia. Sifat malu yang telah diajarkan sejak kecil akan terbawa hingga dewasa (Effendy, 2015), dan saat ia bekerja. Dalam penelitianpenelitian sebelumnya, telah banyak dibuktikan bahwa malu dan sifat malu memiliki peranan yang positif di tempat kerja. Malu merupakan sebuah emosi yang sangat kuat yang dapat digunakan dalam meningkatkan kinerja pegawai (Martinez, Ferreira, \& Cunha, 2011). Dalam penelitian tersebut, malu yang dirasakan pegawai akan meningkatkan motivasi yang kemudian akan meningkatkan kinerja dan perilaku prososial. Malu juga mengarahkan upaya pekerja untuk memulihkan ikatan sosial dengan kolega dan konsumennya dengan meningkatkan perilaku altruistic mereka (Bagozzi, Verbeke, \& Gavino, 2003). Penelitian yang dilakukan di Kota Pekanbaru menunjukkan bawa malu berkorelasi negatif terhadap cyberloafing (Ihsani, Suadana, Muis, Aiyuda, \& Nasution,
2018). Rasa malu merupakan alat penting untuk membuat individu mematuhi normanorma sosial (Andrews, 1998).

Gilbert (1998) menyatakan bahwa sifat malu berhubungan dengan perilaku kepatuhan. Rasa malu akan mendorong kehati-hatian, kepatuhan dan rasa hormat. Dengan demikian, semestinya orang yang memiliki sifat malu akan bekerja dengan hatihati, mengikuti aturan serta menunjukkan hubungan interpersonal yang baik sehingga cenderung mengindari perilaku kerja kontraproduktif. Namun, meskipun orang melayu memiliki sifat malu, tindakan-tindakan kontraproduktif masih saja sering terjadi. Dalam menjelaskan perilaku, interaksi individu dengan lingkungannya tidak dapat diabaikan. Lingkungan memiliki peran dalam menstimulus individu untuk memberikan respon.

Tett et al. (2013) menjelaskan bahwa sifat dan situasi tidak bisa dipisahkan dalam menjelaskan perilaku, dimana latent trait diekspresikan dalam perilaku kerja sebagai reaksi terhadap isyarat situasional yang relevan dengan sifat. Disaat isyarat situasional yang berupa iklim etik yang positif relevan untuk mengekspresikan sifat malu menjadi perilaku kerja yang menghindari pelanggaran, barusaha mencapai standar, mengikuti aturan, menjalankan ajaran agama dan mengikuti norma social maka pegawai tidak melakukan perilaku kerja kontraproduktif. Relevansi trait dengan isyarat situasional akan menghasilkan intrinsic reward sebagai kepuasan. Orang-orang dengan sifat malu merasakan kepuasan saat iklim etik unit kerjanya mendukungnya mengekspresikan trait tersebut dalam perilaku kerja etik.

Penelitian ini membuktikan bahwa pengaruh sifat malu terhadap perilaku kontraproduktif ditentukan oleh positif/ negatifnya iklim etik yang dipersepsi oleh pegawai. Iklim etik yang positif memperkuat pengaruh sifat malu dalam menurunkan 
perilaku kerja kontraproduktif, sementara iklim etik yang negatif justru melemahkan pengaruh sifat malu terhadap menurunkan perilaku kerja konteproduktif. Pegawai yang memiliki kecenderungan malu, akan menilai dirinya buruk jika melakukan tindakan yang oleh diri dan lingkungannya dinilai tidak sesuai, tidak patut dan tidak terpuji. Namun, jika ia mempersepsi bahwa sebagian besar orang-orang di unit kerjanya tidak perduli akan pelanggaran, menonjolkan nilai-nilai yang mengutamakan pencapaian pribadi, sering menampilkan tidakan tidak etis, dapat memperlemah pengekspresian sifat malunya sehingga ikut menampilkan perilaku kontraproduktif. Demikian pentingnya iklim etik yang positif perlu dibentuk dan dijaga agar pegawai dapat mengekspresikan sifat malunya dalam perilaku patuh pada aturan dan hormat terhadap sesama sehingga dapat mencegah perilaku kerja kontraproduktif.

\section{Kesimpulan}

Sifat malu mempengaruhi perilaku kerja kontraproduktif dengan iklim etik sebagai moderator. Sifat malu sebagai sebuah trait akan terwujud dalam tindakan yang sesuai dengan trait jika isyarat situasional memberi tempat untuk mewujudkannya. Iklim etik yang dipersepsi positif menjadi isyarat situasional bagi individu dengan sifat malu untuk mengekspresikan kerentanannya dalam merasakan malu melakukan pelanggaran aturan, standar dan norma sosial sehingga tidak melakukan perilaku kerja kontraproduktif. Oleh karena itu, selain berusaha untuk menanamkan dan menjaga sifat malu dalam melanggar aturan, pemerintah perlu membentuk iklim kerja yang kondusif agar pegawai menunjukkan perilaku kerja yang positif.

Perilaku kerja kontraproduktif sangat luas dan banyak bentuknya. Oleh sebab itu, untuk peneliti selanjutnya dapat meneliti dan menguji model ini secara lebih spesifik untuk perilaku kerja kontraproduktif tertentu. Selain itu, dapat pula menambahkan instrumen lainnya sebagai penguat dan pembanding data perilaku kontraproduktif sehingga didapatkan data yang lebih objektif.

\section{Daftar Pustaka}

Abraham, J., \& Berline, R. P. N. (2015). An Investigation on Organizational Charlatan Behaviour and Moral Identity as Predictors of Shame: Importance for Education. Journal of Education and Learning (EduLearn), 9(2), 135144. https://doi.org/10.11591/edulearn. v9i2.1535

Aknouche, N., \& Noor, N. M. (2014). The Primacy of the Self in Shame: Can Shame be Benevolent? American International Journal of Social Science, 3(1), 59-79.

Arnaud, A. (2006). A New Theory and Measure of Ethical Work Climate: The Psychological Process Model ( PPM) and the Ethical Climate Index ( $\mathrm{ECl})$. University of Central Florida, Orlando, Florida.

Bagozzi, R. P., Verbeke, W., \& Gavino, J. C. (2003). Culture Moderates the SelfRegulation of Shame and Its Effects on Performance : The Case of Salespersons in the Netherlands and the Philippines. Journal of Applied Psychology, 88(2), 219-233. https://doi.org/10.1037/00219010.88.2.219

Bauer, J. A., \& Spector, P. E. (2015). Discrete Negative Emotions and Counterproductive Work Behavior. Human Performance, 28(4), 307-331. https://doi.org/10.1080/08959285.2015. 1021040

Bedford, O. A. (2004). Culture \& Psychology The Individual Experience of Guilt and Shame in Chinese Culture. Culture and Psychology, 10(29). https://doi. org/10.1177/1354067X04040929

Bisht, N. S., \& Mahajan, A. (2021). Shared stressors and core self-evaluations: A 
trait activation perspective on employee performance. Journal of Business Research, 131(April), 103-111. https:// doi.org/10.1016/j.jbusres.2021.03.053

Chen, C., Chen, M. Y., \& Liu, Y. (2013). Negative affectivity and workplace deviance : the moderating role of ethical climate. The International Journal of Human Resource Management, 24(15), 2894-2910. https://doi.org/10.1080/095 85192.2012.753550

Cohen, T. R., Panter, A. T., Turan, N., Morse, L., \& Kim, Y. (2014). Moral Character in the Workplace. Journal of Personality and Social Psychology, 107(5), 943-963.

Cucuani, H., Sulastiana, M., Harding, D., \& Agustiani, H. (2020). Adaptation and Validation of the Indonesian Version of Counterproductive Work Behavior Checklist ( CWB-C ): In Association with Customer-Oriented Organizational Citizenship Behavior on Indonesian Public Sector-Employees, 12(1), 59555965.

Cucuani, H., Sulastiana, M., Harding, D., \& Agustiani, H. (2021). The Meaning of Shame for Malay People in Indonesia and Its Relation to Counterproductive Work Behaviors in the Fourth Industrial Revolution. In C.-H. Mayer, E. Vanderheiden, \& P. T. P. Wong (Eds.), Shame 4.0: Investigating an Emotion in Digital Worlds and the Fourth Industrial Revolution (pp. 73-86). Springer. https:// doi.org/https://doi.org/10.1007/978-3030-59527-2_4

Effendy, T. (2015). Tunjuk Ajar Melayu. Pekanbaru: Dinas Pendidikan dan Kebudayaan Pemerintah Propinsi Riau bekerja sama dengan Tenas Effedy Foundation.

Fida, R., Paciello, M., Tramontano, C., Reid, •, Fontaine, G., Barbaranelli, C., \& Farnese, M. L. (2015). An Integrative Approach to Understanding Counterproductive Work Behavior: The
Roles of Stressors, Negative Emotions, and Moral Disengagement. Journal of Business Ethics, 130, 131-144. https:// doi.org/10.1007/s10551-014-2209-5

Fornell, C., \& Larcker, D. F. (1981). Evaluating Structural Equation Models with Unobservable Variables and Measurement Error. Journal of Marketing Research, 18(1), 39-50. Retrieved from http://www.jstor.org/stable/3151312 .

Fox, S., Spector, P. E., \& Miles, D. (2001). Counterproductive Work Behavior (CWB) in Response to Job Stressors and Organizational Justice: Some Mediator and Moderator Tests for Autonomy and Emotions. Journal of Vocational Behavior, 59(3), 291-309. https://doi. org/10.1006/jvbe.2001.1803

Gilbert, P. (1998). What is shame? Some core issues and controversies. In P. Gilbert \& B. Andrews (Eds.), Shame: Interpersonal Behavior, Psychopathology, and Culture (pp. 3-38). New York: Oxford Universiry Press.

Goddard, C. (1996). The "Social Emotions " of Malay ( Bahasa Melayu ). Ethos, 24(3), 426-464. https://doi.org/10.1525/ eth.1996.24.3.02a00020

Hu, L., \& Bentler, P. M. (1999). Cutoff criteria for fit indexes in covariance structure analysis : Conventional criteria versus new alternatives. Structural Equation Modeling: A Multidisciplinary Journal, 6(1), 1-55. https://doi.org/10. 1080/10705519909540118

Ihsani, I. N. M., Suadana, S., Muis, I. A., Aiyuda, N., \& Nasution, I. N. (2018). Shame and Guilt Toward Cyberloafing of Malay Students in Pekanbaru, Riau. In The 1st International Conferences on Islamic Psychology. Yogyakarta.

Joseph F. Hair, J., Black, W. C., Babin, B. J., \& Anderson, R. E. (2019). Multivariate Data Analysis: Multivariate Data Analysis: Why multivariate data analysis? (8th ed.). Annabel Ainscow. 
Judge, T. A. (2015). SITUATION STRENGTH AND TRAIT ACTIVATION ON THE The Person-Situation Debate Revisited: Effect of Situation Strength and Trait Activation on the Validity of the Big Five Personality Traits in Predicting Job Performance TIMOTHY A . JUDGE Mendoza College of. Amj, 58(4), 1149 1179.

Kanten, P., \& Ulker, F. E. (2013). The Effect of Organizational Climate on Counterproductive Behaviors: An Empirical Study on the Employees of Manufacturing Enterprises. The Macrotheme Review, 2(4), 144-160.

Lewis, M. (1992). Shame: The exposed self. New York: The Free Press.

Lucia Bellora-Bienengräbera, R.Radtke, R., \& K.Widener, S. (2021). Counterproductive work behaviors and work climate: The role of an ethically focused management control system and peers' self-focused behavior. Accounting, Organizations and Society. https://doi.org/https://doi. org/10.1016/j.aos.2021.101275

Martinez, L. F., Ferreira, A. I., \& Cunha, J. V. (2011). Emotions in the workplace: Can shame increase productivity levels ? Retrieved September 1, 2018, from https://www.researchgate.net/publicatio n/323662803\%0AEmotions

Murphy, S. A., \& Kiffin-Petersen, S. (2017). The Exposed Self: A Multilevel Model of Shame and Ethical Behavior. Journal of Business Ethics, 141, 657-675. https:// doi.org/10.1007/s10551-016-3185-8

Pagliaro, S., Presti, A. Lo, Barattucci, M., Giannella, V. A., \& Barreto, M. (2018). On the Effects of Ethical Climate ( $\mathrm{s}$ ) on Employees 'Behavior: A Social Identity Approach. Original Research, 9(960), 1-10. https://doi.org/10.3389/ fpsyg.2018.00960

Penney, L. M., \& Spector, P. E. (2002). Narcissism and Counterproductive Work Behavior: Do Bigger Egos Mean
Bigger Problems? International Journal of Selection and Assessment, 10(1\&2), 126-134. https://doi.org/10.1111/14682389.00199

Philip, J. (2021). A multi-study approach to examine the interplay of proactive personality and political skill in job crafting. Journal of Management and Organization, (May). https://doi.org/10. 1017/jmo.2021.1

Roxana, A.-C. (2013). Antecedents and Mediators of Employees' Counterproductive Work Behavior and Intentions to Quit. Procedia - Social and Behavioral Sciences, 84, 219-224. https://doi.org/10.1016/j.sbspro.2013. 06.538

Sackett, P. R., \& Devore, C. J. (2005). Counterproductive Behaviors at Work. In N. Anderson, D. S. Ones, H. K. Sinangil, \& C. Viswesvaran (Eds.), Handbook of Industrial, Work on Organizational Psychology (pp. 145-164). London: SAGE Publications Inc.

Spector, P. E., \& Domagalski, T. (2006). Emotions, Violence, and Counterproductive Work Behavior. In E. K. Kelloway, J. Barling, \& J. J. H. Jr. (Eds.), Handbook of Workplace Violence (pp. 29-46). Tampa: Sage Publications. https://doi.org/10.4135/9781412976947. n3

Spector, P. E., \& Fox, S. (2002). An emotioncentered model of voluntary work behavior: Some parallels between counterproductive work behavior and organizational citizenship behavior. Human Resource Management Review, 12(2), 269-292. https://doi.org/10.1016/ S1053-4822(02)00049-9

Spector, P. E., \& Fox, S. (2005). The StressorEmotion Model of Counterproductive Work Behavior. In S. Fox \& P. E. Spector (Eds.), Counterproductive work behavior: Investigations of actors and targets. (pp. 151-174). Washington. https://doi. 
org/10.1037/10893-007

Spector,P.E., Fox, S.,Penney, L.M.,Bruursema, K., Goh, A., \& Kessler, S. (2006). The dimensionality of counterproductivity: Are all counterproductive behaviors created equal? Journal of Vocational Behavior, 68(3), 446-460. https://doi. org/10.1016/j.jvb.2005.10.005

Su, C. (2010). A Cross-Cultural Study on the Experience and Self-Regulation of Shame and Guilt. Soil Science. Toronto.

Suparlan, P. (1995). Orang Sakai di Riau: Masyarakat terasing dalam masyarakat Indonesia. Jakarta: Yayasan Obor Indonesia.

Tangney, J.P., \& Tracy, J. L. (2012). SelfConscious Emostions. In M. R. Leary \& J. P. Tangney (Eds.), Handbook of Self and Identity (2nd ed., pp. 446479). The Guilford Press. https://doi. org/10.4135/9781446263402

Tangney, June Price, \& Dearing, R. L. (2002). Shame and Guilt. (P. Salovey, Ed.). New York: The Guilford Press.

Tangney, June Price, Stuewig, J., \& Mashek, D. J. (2007). Moral Emotions and Moral Behavior. The Annual Review of Psychology, 58, 345-372. https:// doi.org/10.1146/annurev.psych. 56.091103.070145

Tett, R. P., \& Guterman, H. A. (2000). Situation Trait Relevance, Trait Expression, and Cross-Situational Consistency: Testing a Principle of Trait Activation Borne of the long-standing debate over traits and situations as sources of behavioral variance ( Bowers , 1973 ; Ekehammar , 1974 ; Journal of Research in Personality, 34, 397-423. https://doi.org/10.1006/ jrpe.2000.2292

Tett, R. P., Simonet, D. V, \& Brown, C. (2013). Trait activation theory: Applications, developments, and implications for person-workplace fit. In Christiansen \& Tett (Eds.) (pp. 71-100).
Tim penyusunan Laporan Tahunan KPK 2017. (2018). Laporan Tahunan 2017: Demi Indonesia untuk Indonesia. Retrieved November 23, 2018, from www.kpk. go.id/Laporan Tahunan KPK 2017

Tinsley, C. H., \& Weldon, E. (2003). Responses to a Normative Conflict Among American and Chinese Managers. International Journal of Cross-Cultural Management, 3(2), 183-194. https://doi. org/10.1177/14705958030032003

Wang, J., \& Wang, X. (2012). Structural Equation Modeling. $(\mathrm{H}$. Balding, D.J., Cressie, N.A.C., Fitzmaurice, G.M., Goldtein, Ed.). India: Wiley. 